\title{
Bioactivity Study of Streptomycin Sulfate loaded Chitosan/Bioglass Scaffold
}

\author{
A. A. Al-esnawy ${ }^{\mathrm{a}}$, A. S. Abdraboh ${ }^{\mathrm{a}, \hat{a}}$, A. M. Bakr ${ }^{\mathrm{b}}$, K. T. Ereba ${ }^{\mathrm{a}}$. \\ a Physics Department, Faculty of Science, Al-Azhar University, Nasr City, Cairo \\ 11884, and ${ }^{b}$ Spectroscopy Department, Physics Research Division, National Research \\ Centre, 33 El Bohouth St., Dokki, Giza 12622, Egypt.
}

\begin{abstract}
NOVEL type of drug-delivery scaffold based on bioactive glass (BG) and of Chitosan A CH) loaded with Streptomycin Sulfate (STRS) were prepared by improved freeze-drying. we synthesized a BG using the sol-gel method, mixed with a constant ratio of $\mathrm{CH}$ (BG:CH = 1:1 wt \%). So, we have two samples: $\mathrm{CH} / \mathrm{BG}$ ( $0 \%$ STRS) and STRS-loaded CH/BG (20\% STRS) scaffold. The development of new composite scaffolds based on the combination of $(\mathrm{CH})$ with (BG) scaffolds as a carrier to an antibiotic drug (STRS) for the application in bone tissue engineering. In this work, $\mathrm{CH} / \mathrm{BG}$ and STRS-loaded $\mathrm{CH} / \mathrm{BG}$ scaffolds. The obtained materials were characterized by different techniques X-ray diffraction (XRD), Fourier transformed infrared spectroscopy (FTIR), Field Emission Gun Scanning Electron Microscopy (FEG-SEM), and Energy Dispersive X-ray Analysis (EDXA) before and after soaking in (SBF). Bioactivity results of the prepared scaffolds showed exhibits a deposition of a layer of Calcium Phosphate on their surfaces. The results showed that the scaffolds had high porosity with open pores. Furthermore, the BG particles were homogenously distributed within the scaffolds. According to the obtained results, STRS-loaded CH/BG (20\% STRS) sample has higher bioactivity than CH/BG (0\% STRS) sample.
\end{abstract}

Keywords: Bioglass/Chitosan, Scaffold, Streptomycin Sulfate, Bioactivity, antibacterial

\section{Introduction:}

Bone regeneration is one of the greatest difficulties in clinical surgery because many diseases, including trauma, tumors, and bone diseases such as osteitis and osteomyelitis, can cause bone defects. Many solutions have been used in therapy and research to restore normal bone structure and function, including autografts, allografts, xenografts, and other artificial substitutes. To address this situation, biomaterials have been used to create three-dimensional (3D) structures called scaffolds, which offer more advantages than powders, granulated materials, or even some of them before the aforementioned transplants. These scaffolds can induce bone regeneration and can degrade after a certain time after implantation [1], [2]. Recently, three-dimensional porous scaffolds loaded with specific living cells have been researched to regenerate tissue naturally,[3] 4]].
Once the tissue is restored, the body itself reabsorbs and removes the ideal biomaterial or integrates it into the new tissue without the need for additional surgery [5], [6]. In this context, the scaffold, a highly porous material, should act as a 3D template for cell adhesion, proliferation, migration, and ultimately for the formation of new tissue [7]. The scaffold's bioactivity also increases with the incorporation of materials that can interact or bind to living tissues. Increased bioactivity of the scaffold can, in turn, lead to better growth of bone cells (Osteoconduction), stable anchoring of scaffolds to host bone tissue (osseointegration), stimulation of immature host cells to develop osteogenic cells (Osteoinduction), and increased vascularity.

Biocomposites based on biodegradable polymers and bioactive ceramics were developed for applications in bone repair and reconstruction. For this, due to their proven biocompatibility 
and complete bioresorbability, various polymers are often used such as polylactic acid (PLA), polyglycolic acid (PGA), polylactic acid-coglycolic acid (PLGA), gelatin, alginate and chitosan $(\mathrm{CH})[8]$, [9].

Among biodegradable polymers, chitosan has recently gained interest due to its special physiological properties. Chitosan is a natural polymer that can be obtained by partially deacetylating chitin extracted from crustaceans. It is considered appropriate Functional material for biomedical applications due to its good biocompatibility, biodegradability, nonantigenicity, antitumor activity, anti-inflammatory effect, protein adsorption properties and ability to Accelerated wound healing. Due to its structural similarity to glycosaminoglycans, a major component of bone and cartilage, chitosan plays an important role in the attachment, differentiation, and morphogenesis of osteoblasts, the bone-forming cells [10].

Streptomycin is an antibiotic produced as a metabolic product by Streptomyces globisporos streptomycin or another similar organism [11]. It is effective against a wide variety of bacteria and is used in particular to treat tuberculosis. The main disadvantages of streptomycin are insufficient penetration into cells due to its hydrophilicity, rapid elimination due to efficient renal filtration and low association with plasma proteins, and severe side effects such as permanent deafness and renal toxicity [12]. The Chitosan/Bioglass beads were synthesized Carrier of an antibiotic streptomycin sulfate (STRS) [13]. Bioactivity analysis showed that apatite layer was formed on it. the surface of the composite beads due to the creation of porosity by the addition of the drug STRS

This study presents a simple but efficient method to prepare $\mathrm{CH} / \mathrm{BG}$ composite scaffolds impregnated with STRS with a porous structure. This technique involved the preparation of precursors, co-precipitation, molding, and consequent freeze-drying. Freeze-drying or lyophilization is one of the principal scaffold fabrication techniques, in which the sublimation is employed to remove water from $\mathrm{CH} / \mathrm{BG}$ and STRS-loaded $\mathrm{CH} / \mathrm{BG}$ solution.

\section{Materials and Methods:}

\section{Materials:}

Tetra-Ethyl-Ortho-Silicate (TEOS: $\mathrm{C}_{8} \mathrm{H}_{20} \mathrm{O}_{4} \mathrm{Si}$, $\mathrm{Mw}=208.33 \mathrm{~g} / \mathrm{mol}$ ), Calcium Nitrate Tetrahydrate Egypt. J. Biophys. Biomed. Eng., Vol. 22 (2021)
$\left(\mathrm{Ca}\left(\mathrm{NO}_{3}\right)_{2} \cdot 4 \mathrm{H} 2 \mathrm{O}, \mathrm{Mw}=236.14892 \mathrm{~g} / \mathrm{mol}\right)$, TetriEthyl-Phosphate (TEP: $\mathrm{C}_{6} \mathrm{H}_{15} \mathrm{O}_{4} \mathrm{P}, \mathrm{Mw}=182.15 \mathrm{~g} /$ $\mathrm{mol})$, and $2 \mathrm{M}$ Nitric acid $\left(\mathrm{HNO}_{3}\right)$ were purchased from Merck Inc (Darmstadt, Germany). Acetic acid $(96 \%)$ and Chitosan $\left(\mathrm{CH}: \mathrm{C}_{56} \mathrm{H}_{103} \mathrm{~N}_{9} \mathrm{O}_{39}, \mathrm{Mw}=\right.$ $1526.5 \mathrm{~g} / \mathrm{mol}$, degree of deacetylation $=85 \%$ ) were purchased from Sigma-Aldrich Co USA. Streptomycin Sulfate (STRS: $\mathrm{C}_{42} \mathrm{H}_{84} \mathrm{~N}_{14} \mathrm{O}_{36} \mathrm{~S}_{3}$, $\mathrm{Mw}=1457.4 \mathrm{~g} / \mathrm{mol}$ ), were purchased from Panacea Biotec Ltd. (Lalru, Punjab, India). All the other chemicals for the simulated body fluid (SBF) were purchased from Sigma-Aldrich (St. Louis, MO, USA).

Production of bioactive glass $(B G)$

The bioactive glass was prepared by a solgel technique with an average ratio of (58 wt \% $\mathrm{SiO}_{2}, 36$ wt $\% \mathrm{CaO}, 6$ wt $\% \mathrm{P}_{2} \mathrm{O}_{5}$ ) powder was synthesized according to (Al-esnawy, A. A., et al, 2020) [13]. Briefly, $43.544 \mathrm{ml}$ TEOS was added into $7.525 \mathrm{ml}$ of $2 \mathrm{M}$ Nitric acid $\left(\mathrm{HNO}_{3}\right)$, then the mixture could react for $30 \mathrm{~min}$ to promote the acid hydrolysis of TEOS. The following reagents were added in sequence, allowing $45 \mathrm{~min}$ for each reagent to react: $2.842 \mathrm{ml}$ TEP, and $30.626 \mathrm{~g}$ of Calcium Nitrate Tetrahydrate $\left(\mathrm{Ca}\left(\mathrm{NO}_{3}\right)_{2} \square 4 \mathrm{H}_{2} \mathrm{O}\right.$, $\mathrm{Mw}=236.14892 \mathrm{~g} / \mathrm{mol}$ ).

Then, the mixture kept under stirring for 1.5 hours until hydrolysis. The solution was heated at $120{ }^{\circ} \mathrm{C}$ for 3 days to evaporate all the water. After that, the powder heated $3 \mathrm{~h}$ at $600{ }^{\circ} \mathrm{C}$ to remove the toxic nitrate ions and incorporate calcium into the silicate network [14]. BG powders were deagglomerated in a mortar agate. Then, BG powders were sieved at $90 \mu \mathrm{m}$.

Synthesis of STRS-loaded CH/BG scaffolds composite scaffolds

The STRS-loaded CH/BG scaffolds composite hydrogel with different contents of STRS were prepared; The STRS-loaded Scaffolds have been prepared with constant ratio $(1: 1)$ wt $\%$ of the synthesized $\mathrm{CH} / \mathrm{BG}$ and a ratio of STRS as listed in (Table 1).

For the preparation of the STRS-loaded scaffolds; (1, and $0.8 \mathrm{~g}$ ) chitosan polymer was dissolved in $1 \%$ acetic acid solution under moderate magnetic stirring ( 2 hours) at $65{ }^{\circ} \mathrm{C}$. Different percentages $(0 \%$, and $20 \%)$ of STRS have been added to the BG and stirred for 2 hours at room temperature; the mixture (STRS-loaded $\mathrm{CH} / \mathrm{BG}$ ) precursor's solution was mechanically mixed using a homogenizer with a rotating speed of 969 rpm [High-Torque Digital Overhead 
TABLE 1: Chemical composition of Two grams of STRS-loaded CH/BG Scaffolds in (wt \%).

\begin{tabular}{|c|c|c|c|c|c|}
\hline \multirow{2}{*}{ Sample Code } & \multirow{2}{*}{$\begin{array}{c}\text { CH/BG } \\
\% \text { wt (1:1) }\end{array}$} & \multirow{2}{*}{ (CH (g } & \multirow{2}{*}{ (BG (g) } & \multicolumn{2}{|c|}{ STRS } \\
\hline & & & & $\% w \mathrm{t}$ & (g) \\
\hline $\mathrm{CH} / \mathrm{BG} 0 \%$ & $\% 100$ & 1 & 1 & $\% 0$ & 0 \\
\hline $\mathrm{CH} / \mathrm{BG} 20 \%$ & $\% 80$ & 0.8 & $8 . .^{\circ}$ & $\% 20$ & 0.4 \\
\hline
\end{tabular}

Stirrer, “HT-50DX” homogenizer (Germany)] for 2 hours until fully the solvent had completely homogenized.

\section{In vitro bioactivity study}

The bioactive behavior of $\mathrm{CH} / \mathrm{BG}$ and STRS loaded composite scaffold was assessed in vitro by immersion in the simulated body fluid (SBF) using the standard protocol introduced by (Kokubo \& Takadama, 2006)[15]. Samples were immersed in the SBF solution at a concentration of $2.5 \mathrm{~g} / \mathrm{L}$ in closable containers for 28 days at 37 ${ }^{\circ} \mathrm{C}$. Upon removing from $\mathrm{SBF}$, the samples were rinsed with distilled water and left to dry.

\section{Characterization}

The samples of $\mathrm{CH} / \mathrm{BG}$ and STRS-loaded $\mathrm{CH} / \mathrm{BG}$ composite scaffold before and after immersion in the SBF solution were investigated by using several physicochemical techniques.

Identification of the developed phases, amorphous or crystalline nature of the surfaces of the scaffold samples was carried out using X-ray powder diffractometer (XRD); model (BRUKER Germany, D8 ADVANCE) with a copper target $\left(\mathrm{Cu} \mathrm{k} \alpha=1.54060 \mathrm{~A}^{\circ}\right)$ and Nickel filter, ranging $2 \theta$ from $0^{\circ}$ to $60^{\circ}$ using a step size of $0.014^{\circ}$ with 1 second per step.

Fourier transformed infrared spectroscopy (FTIR) (Nicolet 6700, Thermo Scientific, USA) was employed to identify the functional groups of the prepared $\mathrm{BG}$ and STRS-loaded $\mathrm{CH} / \mathrm{BG}$ composite scaffolds. Fine powders of the samples mixed with $\mathrm{KBr}$ powder in the ratio 1:100 and the mixture subjected to a load of 10 tons/ $\mathrm{cm}^{2}$ to produce a disc. Spectra were recorded in the absorbance mode in the range of 4000 and $400 \mathrm{~cm}^{-1}$ with a resolution of $4 \mathrm{~cm}^{-1}$. For FTIR measurements, the samples were ground, mixed with $\mathrm{KBr}$ (spectroscopy grade, Merck, Germany) and pressed into pellets. The pellets consisted of 1 $\mathrm{mg}$ of sample and $200 \mathrm{mg}$ of $\mathrm{KBr}$.

The morphological surfaces were studied by using Field Emission Gun Scanning Electron Microscopy (FEG-SEM) (XL30, Philips) with an accelerating voltage of $30 \mathrm{kV}$. Specimens were placed on a stub using a carbon sticker and examined under the microscope.

For chemical analysis, were examined in energy dispersive $\mathrm{X}$-ray analysis coupled to the SEM instrument $\left(E D X A ; 30 \mathbf{m m}^{2} \mathrm{Si}\right.$ (Li) $\boldsymbol{R}$ - $\boldsymbol{R S U T \boldsymbol { W }}$ detector) at $15 \mathrm{kV}$ acceleration voltages. EDXA used to compare the intensities of calcium $(\mathrm{Ca})$, phosphor $(\mathrm{P})$ in the resultant scaffolds before and after immersion in SBF.

\section{Results and Discussion:}

XRD of the Bioglass

As shown in Figure 1 (a), the XRD peak of the $\mathrm{BG}$ particle was dispersive and there was no sharp diffraction peak, which demonstrated that the BG particles were typical with an amorphous structure. And at $2 \theta$ of around $23^{\circ}$, there appeared a broad peak that was a typical amorphous structure characteristic peak of silicate glass[16], [17].

\section{FTIR of the Bioglass}

Fourier-transform infrared (FTIR) spectra of the Bioglass powder are shown in Figure 1 (b). The wideband esteemed from $3100 \mathrm{~cm}^{-1}$ to 3600 $\mathrm{cm}^{-1}$ may be appointed to $\mathrm{O}-\mathrm{H}$ stretching due to the strong hydrogen bond of intramolecular and intermolecular type[9], [18]. The broadband observed at $1649 \mathrm{~cm}^{-1}$ corresponds to $\mathrm{O}-\mathrm{H}$ bending vibration of the chemically adsorbed hydroxyl groups on the glass matrix, and broadband at $1384 \mathrm{~cm}^{-1}$ detected due to the stretching mode of the carbonate group [19], [20]. The main absorption bands for the amorphous Bioglasss are observed at 1024, 926, and $480 \mathrm{~cm}^{-}$ ${ }^{1}$, and attributed to $\mathrm{Si}-\mathrm{O}-\mathrm{Si}$ and $\mathrm{Si}-\mathrm{O}$ stretching modes and to the $\mathrm{Si}-\mathrm{O}-\mathrm{Si}$ bending mode, respectively[21]-[23]. These bands are generally observed in amorphous silica glasses [24], [25].

$\underline{\text { XRD of the composite Scaffolds Before and }}$ $\underline{\text { After SBF }}$

The results of the XRD analysis of $\mathrm{CH} / \mathrm{BG}$ biocomposite scaffolds and STRS loaded $\mathrm{CH} /$ BG scaffolds (20\%) before soaking in SBF are shown in figure 2 (a). It can be seen that the 

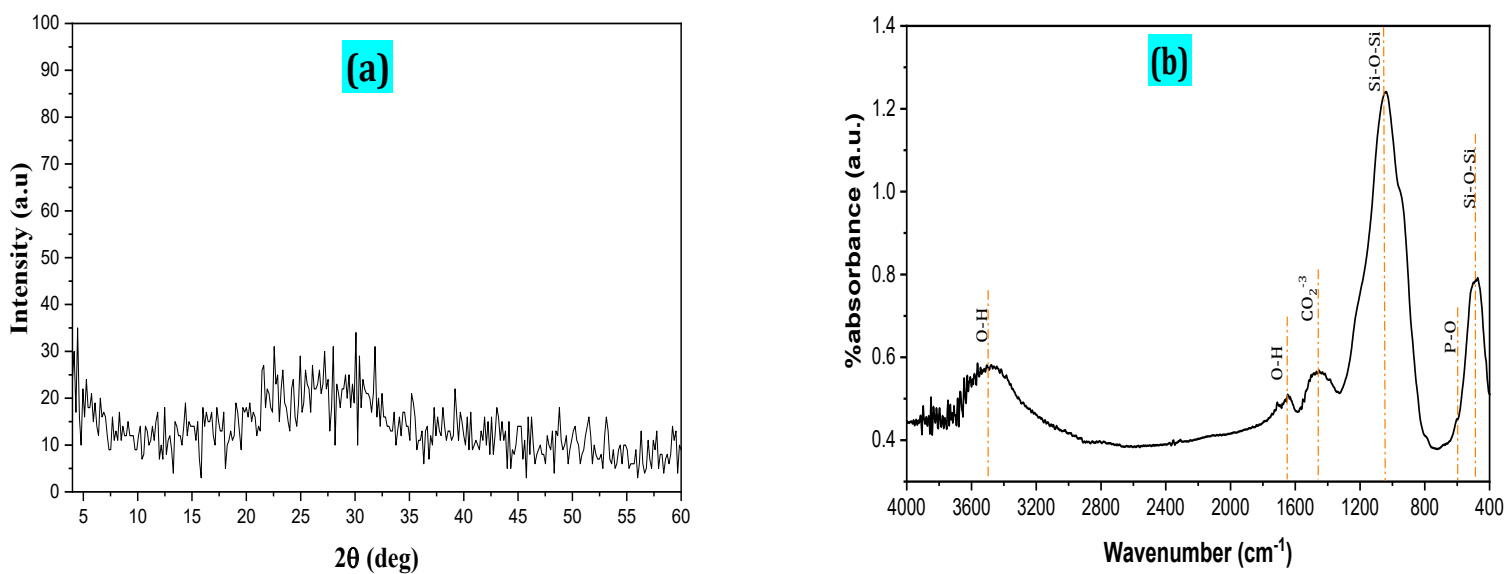

Fig.1. (a) XRD pattern and (b) FTIR spectra of $\mathrm{BG}\left(58 \% \mathrm{SiO}_{2}-36 \% \mathrm{CaO}-6 \% \mathrm{P}_{2} \mathrm{O}_{5}\right)$.
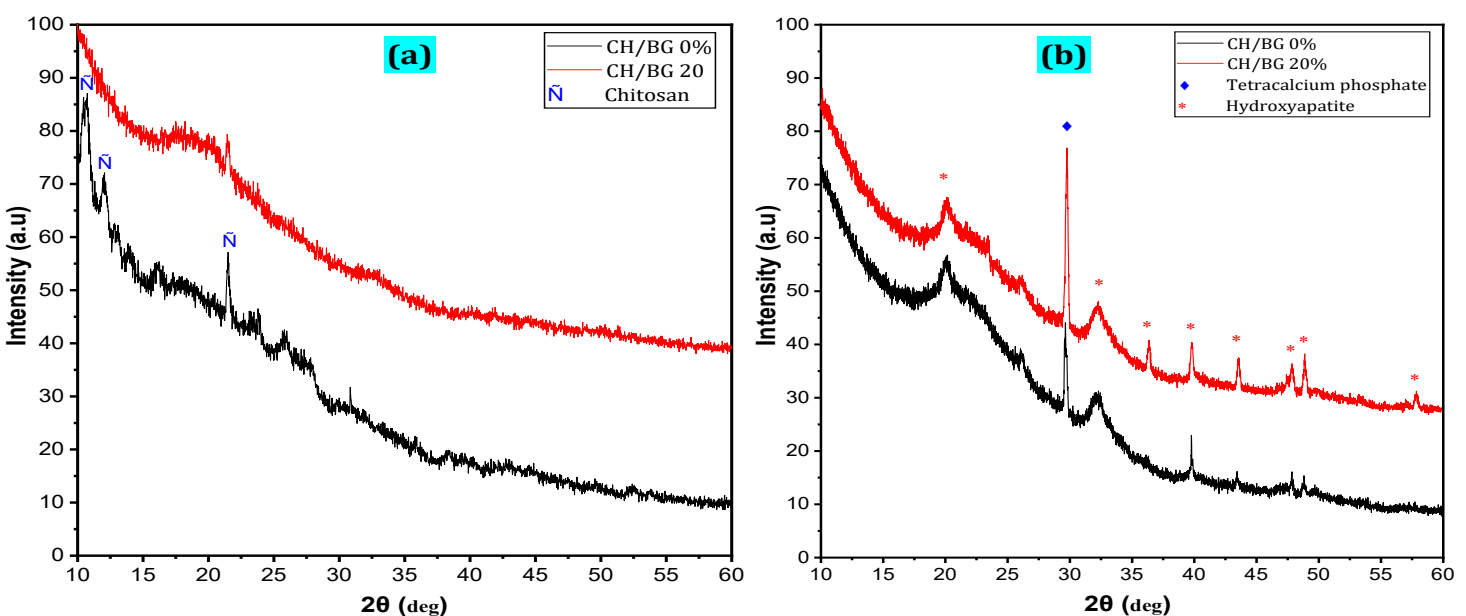

Fig.2. (XRD) patterns of STRS-loaded CH/BG biocomposite Scaffolds (a) before and (b) After immersion in SBF for 28 days.

main characteristic peak $\left(2 \theta=21.5^{\circ}\right)$ of chitosan is present, which means the chitosan was in a crystalline state [26], [27]. The Chitosan peaks are present in the control sample and disappear in the sample containing STRS.

X-ray diffraction (XRD) analyses were performed on all the samples in order to assess the presence of apatite crystalline phases on the $\mathrm{CH} / \mathrm{BG}$ biocomposite scaffolds surfaces after immersion in SBF for 28 days are shown in figure 2 (b). Initially to main peaks of HAp (JCPDS file \#09-0432) [28] were observed at around $2 \theta$ values of $\left(21^{\circ}\right.$ and $\left.32^{\circ}\right)$, these peaks corresponding to (200 and 112) crystal planes. Also, another a small peak located at around $2 \theta$ values $\left(39^{\circ}, 43^{\circ}\right.$, and $\left.48^{\circ}\right)$ corresponding to $(310,113$, and 320$)$ planes. In general, the relative intensity of peaks corresponding to $\mathrm{HAp}$ formation in $\mathrm{CH} / \mathrm{BG} 20 \%$ sample increases than in $\mathrm{CH} / \mathrm{BG} 0 \%$ sample. One sharp peak is founded in all samples at $2 \theta=$ $29.6^{\circ}$ corresponding to tetracalcium phosphate (TeCP) formation [29], [30]. Which means the transformation of (TeCP) to HAp.

\section{FTIR of the composite Scaffolds}

FTIR spectroscopy was used to evaluate the interactions between the polymer $(\mathrm{CH})$, particles (BG), (STRS), and the formation of a HAp layer on the surface of biocomposite scaffolds before and after immersion in SBF.

FTIR spectra before Immersion in $S B F$, the characteristic bands of both $\mathrm{CH} / \mathrm{BG}$ and STRS loaded CH/BG (20\%) biocomposite scaffolds 
were observed in Figure (4). However, several characteristic bands are shifted, deformed, or disappeared. This attributes to some chemical interactions between the bioactive glass, chitosan, and streptomycin sulfate. Both samples mainly show the stretching and bending vibrations of the $\mathrm{Si}-\mathrm{O}-\mathrm{Si}$ bridge.

The bending vibrations of the $\mathrm{Si}-\mathrm{O}-\mathrm{Si}$ and $\mathrm{O}-\mathrm{Si}-\mathrm{O}$ links are assigned characteristic bands between 400 and $500 \mathrm{~cm}^{-1}$ [31], [32]. Then, due to the addition of STRS, rocking vibration $\mathrm{Si}-\mathrm{O}-$ $\mathrm{Si}$ (r) is shifted to low wavelength from $464 \mathrm{~cm}^{-1}$ to $460 \mathrm{~cm}^{-1}$. A weak band at $608 \mathrm{~cm}^{-1}$ and 667 $\mathrm{cm}^{-1}$ can be attributed to the an asymmetric and stretching vibration respectively of $\mathrm{P}-\mathrm{O}-\mathrm{P}$ [31], [33]. Also, a weak band in the range of 760-810 $\mathrm{cm}^{-1}$ corresponds to the stretching vibrations of the $\mathrm{O}-\mathrm{Si}-\mathrm{O}$ bonds, while the increased intensity of bands in the range of $1000-1100 \mathrm{~cm}^{-1}$ is attributed to the symmetric stretching vibration of the $\mathrm{Si}-\mathrm{O}-\mathrm{Si}$ bonds in BG [34], [35]. A shoulder at $946 \mathrm{~cm}^{-1}$, that is related to the non-bridging $\mathrm{Si}-\mathrm{O}-\mathrm{X}(\mathrm{X}=\mathrm{Ca}, \mathrm{H})$ in BG [14]. The weak band located at $\sim 1380 \mathrm{~cm}^{-1}$ can be attributed to $\mathrm{CH}_{3}$ in amide group [36]. The shoulder peak for asymmetric stretch of $\mathrm{C}-\mathrm{O}-\mathrm{C}$ is found at around $1150 \mathrm{~cm}^{-1}$ in Chitosan.
The adsorption of STRS onto chitosan and on BG did not show any significant additional peaks due to its similar functional groups that were overlapped in their peaks in the FTIR spectra of raw BG and chitosan. Deconvolution of the $1365-1730 \mathrm{~cm}^{-1}$ region of all FTIR spectra revealed the presence of STRS (1570 and $1671.8 \mathrm{~cm}^{-1}$ ) Figure (5). Three characteristic bands of chitosan are 1649, 1558 , and $1394 \mathrm{~cm}^{-1}$ indicated to $\mathrm{C}=\mathrm{O}-\mathrm{NH}-$ $\mathrm{CH}_{2}, \mathrm{~N}-\mathrm{H}$, and $\mathrm{C}-\mathrm{N}$ (Amide I, Amide II, and Amide III) respectively [28]. The bands at 2926 and $2880 \mathrm{~cm}^{-1}$ is corresponding to the $-\mathrm{CH}$ - bending vibrations. The broad absorption band at $3000-4000$ is attributed to stretching vibration of $-\mathrm{NH}_{2}$ and $-\mathrm{OH}$ groups [37], [38]. These increased and newly appeared bonds confirmed the successful incorporation of the STRS component into these $\mathrm{CH} / \mathrm{BG}$ scaffolds.

FTIR spectra after Immersion in $S B F$, new peaks at 606 and $569 \mathrm{~cm}^{-1}$ ( $\square \mathrm{P}-\mathrm{O}$ for crystal) were also observed, further supporting the formation and growth of HAp [14]. It has been generally accepted that the bioactivity of a material can be evaluated by the HAp formation[15] Therefore, the STRS-loaded $\mathrm{CH} / \mathrm{BG}$ composite scaffolds were in vitro bioactive. Figure (6).

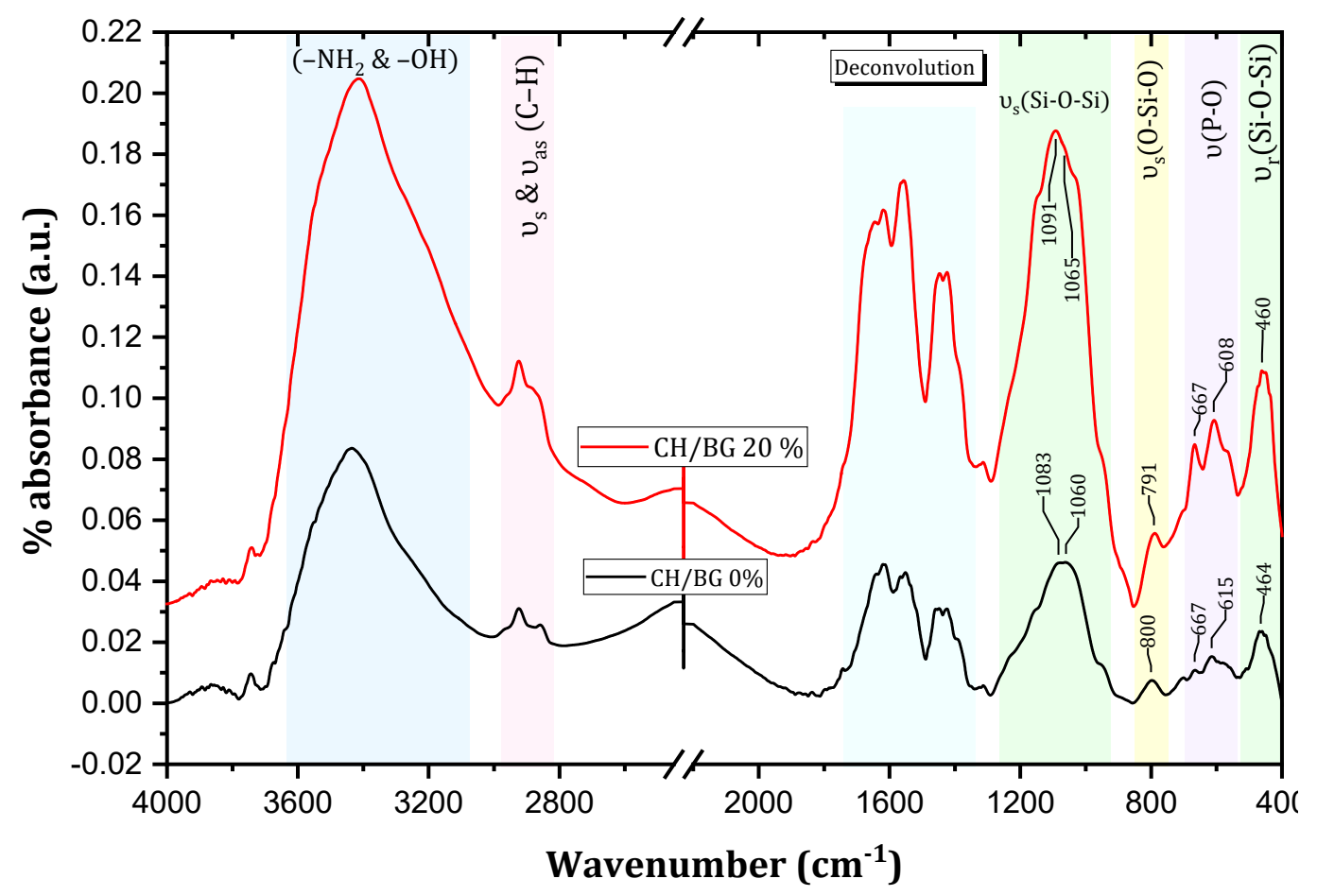

Fig. 4. (FTIR) patterns of STRS-loaded CH/BG biocomposite Scaffolds before immersion in SBF. 


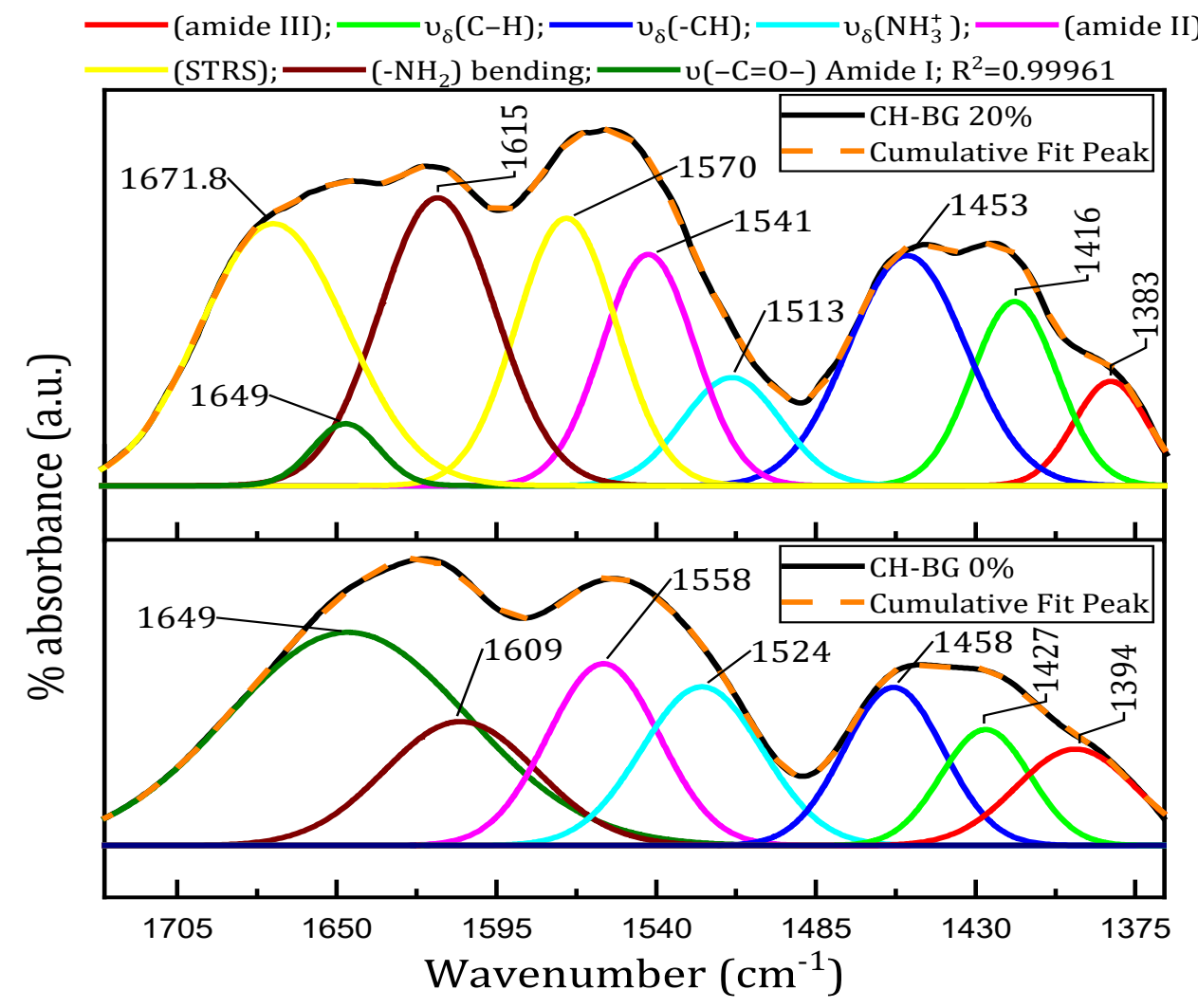

Fig. 5. (FTIR) deconvolution spectrum patterns of STRS loaded CH/BG biocomposite scaffolds before immersion in SBF.

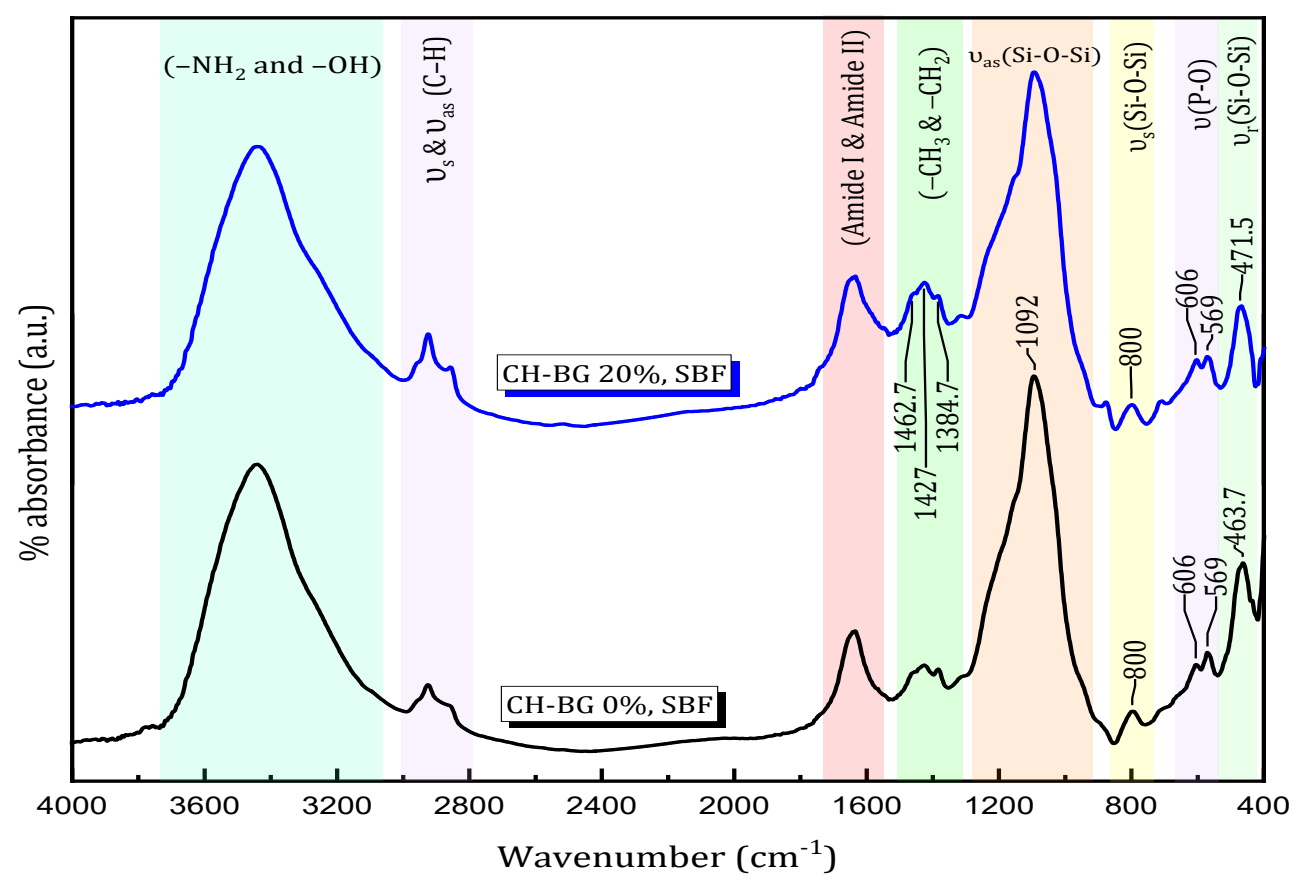

Fig. 6. (FTIR) patterns of STRS loaded CH/BG biocomposite scaffolds after immersion in SBF for 28 days.

Egypt. J. Biophys. Biomed. Eng., Vol. 22 (2021) 


\section{SEM of the composite Scaffolds Before and After} $S B F$

Figure (7) shows the scanning electron microscopy (SEM) image and Energy dispersive $\mathrm{x}$-ray analysis (EDXA) results of $\mathrm{CH} / \mathrm{BG}$ biocomposite scaffolds, and STRS loaded $\mathrm{CH} /$ BG scaffolds $(20 \%)$ before immersion in SBF. CH/BG biocomposite scaffold displayed a microporous membrane structure with interconnected open porous as shown in figure 7 (a). Size of microporous range about $(40 \mu \mathrm{m})$. The morphology of STRS loaded CH/BG scaffolds (20 $\%$ ) displayed that porous membrane structure, but the size of this microporous partially decreased as STRS content increased as shown in figure 7 (b).

In (EDX) elemental analysis of $\mathrm{CH} / \mathrm{BG}$ biocomposite scaffolds, and STRS loaded $\mathrm{CH} / \mathrm{BG}$ scaffolds (20\%), the of peak assigned to Sulfur (S) is found in $\mathrm{CH} / \mathrm{BG} 20 \%$ but disappeared in $\mathrm{CH} / \mathrm{BG}$ biocomposite scaffolds thus confirming the STRS substitution in the prepared $\mathrm{CH} / \mathrm{BG}$ biocomposite scaffolds as intended figure 7 (c) and (d).
Figure (8) shows SEM images and EDXA profiles of $(\mathrm{CH} / \mathrm{BG} \quad 0 \%$ and $\mathrm{CH} / \mathrm{BG} \quad 20 \%$ ) biocomposite scaffolds after immersion in SBF for 28 days. Results displayed that a layer of a flak like crystals of HAp were deposited on the scaffolds surface. Briefly, HAp partially covers the surface of (CH/BG 0\%) sample, but the thickness of this layer mediately increases on (CH/BG 20\%) sample.

EDXA elemental intensities from figure 8 (c) and figure 8 (d) were converted into wt $\%$ and are presented. After immersion in SBF for 28 days EDXA results detected an increase of $\mathrm{Ca}$ and $\mathrm{P}$ concentration, compared with the silicon content. The Si content on the surface of the scaffold samples became extremely low due to the layer of HAp which was formed. $\mathrm{Ca}$ and $\mathrm{P}$ concentration increases in $(\mathrm{CH} / \mathrm{BG} 20 \%)(36.82,7.36 \mathrm{Wt}$.) than in $(\mathrm{CH} / \mathrm{BG} 0 \%)(17.28$ and $3.44 \mathrm{Wt}$.) respectively. It was observed that sample which containing an amount of STRS $(20 \%)$ has a large layer of HAp deposited on it due to its high porosity. This improves that the STRS increase the bioactivity of the prepared samples.

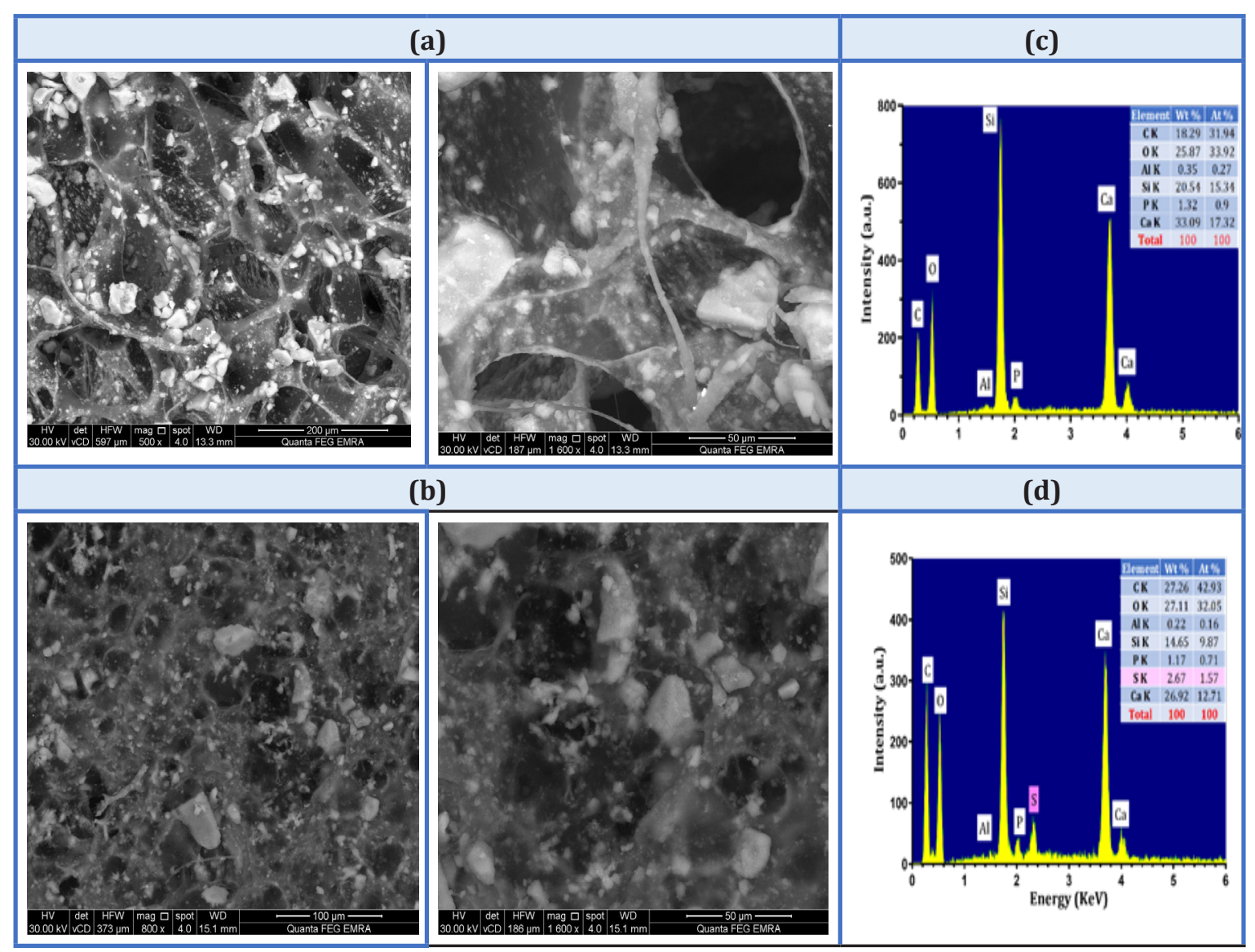

Fig. 7.Scanning Electron Microscopy (SEM) images of, (a) CH/BG 0\%, (b) CH/BG 20\%, and EDXA profiles of (c) $\mathrm{CH} / \mathrm{BG} 0 \%$, (d) $\mathrm{CH} / \mathrm{BG} 20 \%$. Before immersion in $\mathrm{SBF}$. 


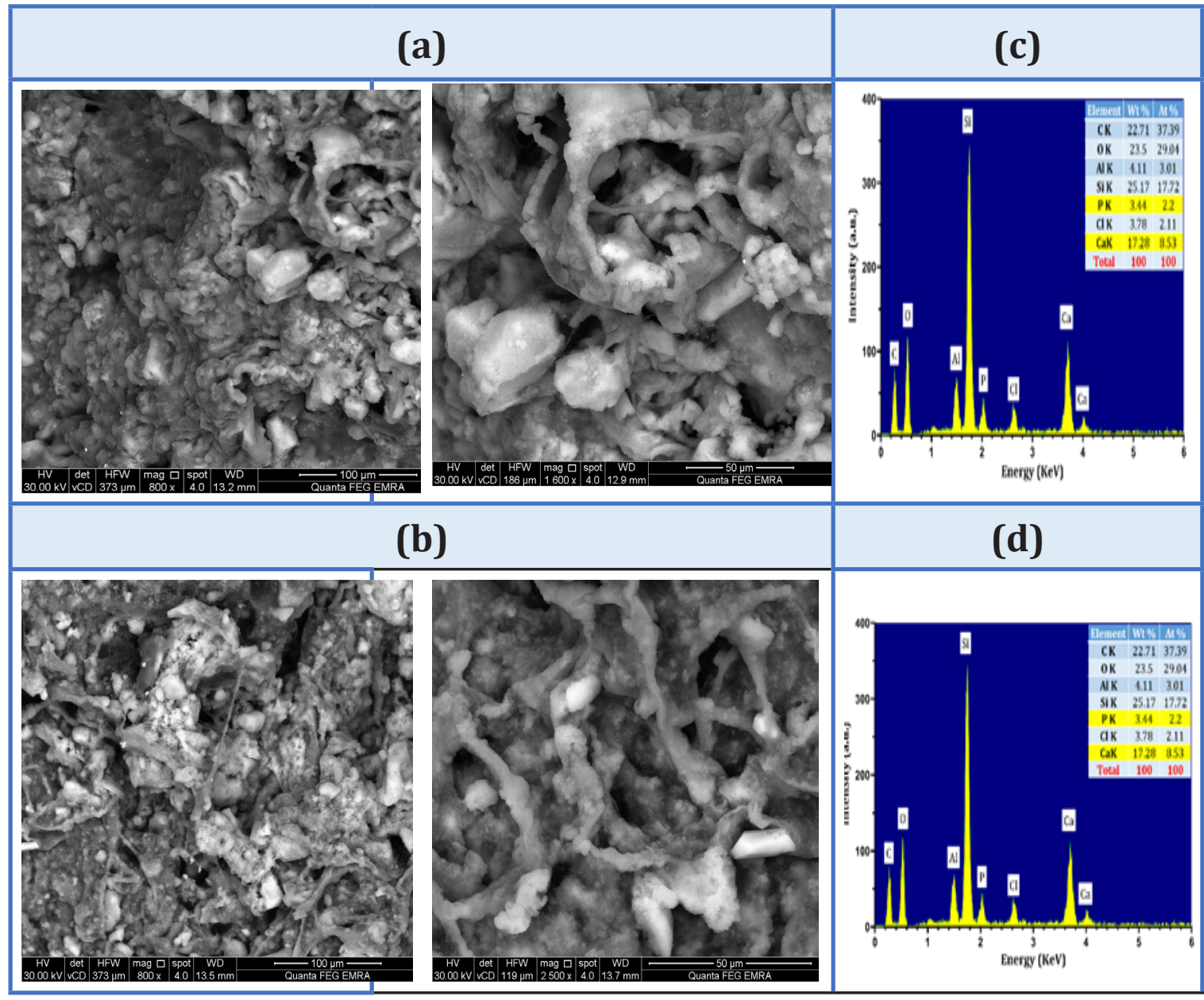

Fig,8.Scanning Electron Microscopy (SEM) images of, (a) CH/BG 0\%, (b) CH/BG 20\%, and EDXA profiles of (c) CH/BG 0\%, (d) CH/BG 20\%. After immersion in SBF for 28 days.

\section{Conclusions}

In this work, Chitosan/Biogalss and Chitosan/Biogalss scaffold with concentration of STRS $(20 \%)$ were prepared using the Freezedrying method. XRD confirms that the main characteristic peak of chitosan is present, which means the chitosan was in a crystalline state. The Chitosan peaks are present in the control sample and disappear in the sample containing STRS before immersion in SBF, the relative intensity of peaks corresponding to $\mathrm{HAp}$ formation in $\mathrm{CH} / \mathrm{BG}$ $20 \%$ sample increases than in $\mathrm{CH} / \mathrm{BG} 0 \%$ sample after immersion in SBF. FTIR analysis revealed specific intermolecular interactions between $\mathrm{CH}$, BG, and STRS. SEM showed porous surface morphology. EDXA profiles exhibited that silica content which act as a network of scaffolds decreased by the addition of STRS.

Bioactivity analysis showed that the apatite layer formed on the surface of the composite scaffold, which confirm that the biological activity of the prepared scaffolds due to the creation of porosity by the addition of the STRS drug.

\section{$\underline{\text { References }}$}

1. J. R. Jones, "Review of bioactive glass: From Hench to hybrids," Acta Biomaterialia, vol. 9, no. 1. Elsevier, pp. 4457-4486, Jan. 01, 2013, doi: 10.1016/j.actbio.2012.08.023.

2. M. Mozafari and F. Moztarzadeh, "Synthesis, characterization and biocompatibility evaluation of sol-gel derived bioactive glass scaffolds prepared by freeze casting method," Ceram. Int., vol. 40, no. 4, pp. 5349-5355, May 2014, doi: 10.1016/j.ceramint.2013.10.115.

3. A. S. Mistry andA. G. Mikos, "Tissue engineering strategies for bone regeneration," Advances in Biochemical Engineering/Biotechnology, 
vol. 94. Springer Science and Business Media Deutschland GmbH, pp. 1-22, Mar. 07, 2005, doi: 10.1007/b99997.

4. D. M. Escobar-Sierra, J. Martins, and C. P. OssaOrozco, "Chitosan/hydroxyapatite scaffolds for tissue engineering manufacturing method effect comparison," Rev. Fac. Ing., vol. 1, no. 75, pp. 24-35, 2015, doi: 10.17533/udea.redin.n75a04.

5. V. Miguez-Pacheco, S. K. Misra, and A. R. Boccaccini, "Biodegradable and bioactive polymer/inorganic phase nanocomposites for bone tissue engineering (BTE)," in Tissue Engineering Using Ceramics and Polymers: Second Edition, 2014, pp. 115-150.

6. V. Mouriño, J. P. Cattalini, W. Li, A. R. Boccaccini, and S. Lucangioli, "Multifunctional scaffolds for bone tissue engineering and in situ drug delivery," in Tissue Engineering Using Ceramics and Polymers: Second Edition, Elsevier Inc., 2014, pp. 648-675.

7. Y. Ikada, "Challenges in tissue engineering," J. R. Soc. Interface, vol. 3, no. 10, pp. 589-601, Oct. 2006, doi: 10.1098/rsif.2006.0124.

8. J. K. Hum, "Bioactive glass combined with natural derived proteins as composite materials for the application in bone tissue engineering," pp. 7281, 2016, doi: 10.1515/bglass-2018-0007.

9. K. Nazemi, F. Moztarzadeh, N. Jalali, S. Asgari, and M. Mozafari, "Synthesis and characterization of poly(lactic-co-glycolic) acid nanoparticles-loaded chitosan/bioactive glass scaffolds as a localized delivery system in the bone defects," Biomed Res. Int., vol. 2014, 2014, doi: 10.1155/2014/898930.

10. X.-V. Bui, H. Oudadesse, Y. Le Gal, A. Mostafa, and G. Cathelineau, Microspheres of ChitosanBioactive Glass for Application in Orthopedic Surgery. In vitro experiment. .

11. Z. S. Nurkeeva, V. V Khutoryanskiy, G. A. Mun, M. V Sherbakova, A. T. Ivaschenko, and N. A. Aitkhozhina, "Polycomplexes of poly(acrylic acid) with streptomycin sulfate and their antibacterial activity," Eur. J. Pharm. Biopharm., vol. 57, no. 2, pp. 245-249, Mar. 2004, doi: 10.1016/S09396411(03)00149-8.

12. V. Coessens, E. Schacht, and D. Domurado, "Synthesis of polyglutamine and dextran conjugates of streptomycin with an acid-sensitive drug-carrier linkage," J. Control. Release, vol. 38, no. 2-3, pp. 141-150, Feb. 1996, doi: 10.1016/0168-3659(95)00111-5.
13. A. A. Al-esnawy, K. T. Ereiba, A. M. Bakr, and A. S. Abdraboh, "Characterization and antibacterial activity of Streptomycin Sulfate loaded Bioglass/ Chitosan beads for bone tissue engineering," J. Mol. Struct., vol. 1227, p. 129715, 2021, doi: 10.1016/j.molstruc.2020.129715.

14. H. Ren, Y. Cui, A. Li, and D. Qiu, "Bioactive glass sol as a dual function additive for chitosan-alginate hybrid scaffold," Chinese Chem. Lett., vol. 29, no. 3, pp. 395-398, Mar. 2018, doi: 10.1016/j. cclet.2018.01.023.

15. T. Kokubo and H. Takadama, "How useful is SBF in predicting in vivo bone bioactivity?," Biomaterials, vol. 27, no. 15, pp. 2907-2915, May 2006, doi: 10.1016/j.biomaterials.2006.01.017.

16. J. Chen, L. Zeng, X. Chen, T. Liao, and J. Zheng, "Preparation and characterization of bioactive glass tablets and evaluation of bioactivity and cytotoxicity in vitro," Bioact. Mater, vol. 3, no. 3, pp. 315-321, Sep. 2018, doi: 10.1016/J. BIOACTMAT.2017.11.004.

17. L. L. Hench, "Bioactive Ceramics: Theory and Clinical Applications," Bioceramics, pp. 3-14, Jan. 1994, doi: 10.1016/B978-0-08-0421445.50005-4.

18. K. Maji, S. Dasgupta, K. Pramanik, and A. Bissoyi, "Preparation and Evaluation of Gelatin-ChitosanNanobioglass 3D Porous Scaffold for Bone Tissue Engineering," Int. J. Biomater, vol. 2016, no. January, 2016, doi: 10.1155/2016/9825659.

19. M. Prabhu, S. Ruby Priscilla, K. Kavitha, P. Manivasakan, V. Rajendran, and P. Kulandaivelu, "In Vitro Bioactivity and Antimicrobial Tuning of Bioactive Glass Nanoparticles Added with Neem (Azadirachta indica) Leaf Powder," Biomed Res. Int., vol. 2014, 2014, doi: 10.1155/2014/950691.

20. Q. Zeng, Y. Han, H. Li, and J. Chang, "Bioglass/ alginate composite hydrogel beads as cell carriers for bone regeneration," J. Biomed. Mater. Res. Part B Appl. Biomater., vol. 102, no. 1, pp. 42-51, 2014, doi: 10.1002/jbm.b.32978.

21. A. R. Boccaccini, Q. Chen, L. Lefebvre, L. Gremillard, and J. Chevalier, "Sintering, crystallisation and biodegradation behaviour of Bioglass ${ }^{\circledR}$-derived glass-ceramics," Faraday Discuss., vol. 136, pp. 27 44, 2007, doi: 10.1039/b616539g.

22. X. Chatzistavrou, T. Zorba, E. Kontonasaki, K. Chrissafis, P. Koidis, and K. M. Paraskevopoulos, "Following bioactive glass behavior beyond

Egypt. J. Biophys. Biomed. Eng., Vol. 22 (2021 
melting temperature by thermal and optical methods," Phys. status solidi, vol. 201, no. 5, pp. 944-951,Apr. 2004, doi: 10.1002/pssa.200306776.

23. H. Aguiar, J. Serra, P. González, and B. León, "Structural study of sol-gel silicate glasses by IR and Raman spectroscopies," J. Non. Cryst. Solids, vol. 355 , no. 8, pp. 475-480, 2009, doi: $10.1016 /$ j. jnoncrysol.2009.01.010.

24. M. R. T. Filgueiras, G. La Torre, and L. L. Hench, "Solution effects on the surface reactions of three bioactive glass compositions," J. Biomed. Mater. Res., vol. 27, no. 12, pp. 1485-1493, Dec. 1993, doi: $10.1002 / \mathrm{jbm} .820271204$.

25. E. Kontonasaki et al., "Hydroxy Carbonate Apatite Formation on Particulate Bioglass In Vitro as a Function of Time," Cryst. Res. Technol., vol. 37 , no. 11, pp. 1165-1171, Nov. 2002, doi: 10.1002/1521-4079(200211)37:11<1165::AIDCRAT1165>3.0.CO;2-R.

26. [26] J. Wang, C. Liu, J. Wei, P. Chi, X. Lu, and M. Yin, "Synthesis and properties of chitosan/ polypeptide bioconjugate composite," Biomed. Mater, vol. 2, no. 1, pp. 32-38, Mar. 2007, doi: 10.1088/1748-6041/2/1/006.

27. M. N. V. R. Kumar, R. A. A. Muzzarelli, C. Muzzarelli, H. Sashiwa, and A. J. Domb, "Chitosan chemistry and pharmaceutical perspectives," Chem. Rev., vol. 104, no. 12, pp. 6017-6084, Dec. 2004, doi: 10.1021/cr030441b.

28. L. Bonetti et al., "Electrophoretic processing of chitosan based composite scaffolds with $\mathrm{Nb}$-doped bioactive glass for bone tissue regeneration," $J$. Mater. Sci. Mater. Med., vol. 31, no. 5, pp. 1-12, May 2020, doi: 10.1007/s10856-020-06378-6.

29. S. Hayakawa et al., "Heterogeneous structure and in vitro degradation behavior of wet-chemically derived nanocrystalline silicon-containing hydroxyapatite particles," Acta Biomater, vol. 9, no. 1, pp. 4856-4867, Jan. 2013, doi: 10.1016/j. actbio.2012.08.024.

30. Y. Otsuka, M. Takeuchi, M. Otsuka, B. BenNissan, D. Grossin, and H. Tanaka, "Effect of carbon dioxide on self-setting apatite cement formation from tetracalcium phosphate and dicalcium phosphate dihydrate; ATR-IR and chemoinformatics analysis," Colloid Polym. Sci., vol. 293, no. 10, pp. 2781-2788, Oct. 2015, doi: $10.1007 / \mathrm{s} 00396-015-3616-6$.

31. Z. Terzopoulou et al., "Composite membranes of poly( $\epsilon$-caprolactone) with bisphosphonate-

Egypt. J. Biophys. Biomed. Eng., Vol. 22 (2021) loaded bioactive glasses for potential bone tissue engineering applications," Molecules, vol. 24, no. 17 , p. 3067 , Aug. 2019, doi: 10.3390/ molecules 24173067 .

32. A. Moghanian, S. Firoozi, and M. Tahriri, "Characterization, in vitro bioactivity and biological studies of sol-gel synthesized $\mathrm{SrO}$ substituted 58S bioactive glass," Ceram. Int., vol. 43, no. 17 , pp. $14880-14890$, Dec. 2017, doi: 10.1016/j.ceramint.2017.08.004.

33. A. López-Noriega, D. Arcos, and M. Vallet-Regí, "Functionalizing mesoporous bioglasses for longterm anti-osteoporotic drug delivery," Chem. - A Eur. J., vol. 16, no. 35, pp. 10879-10886, Sep. 2010, doi: 10.1002/chem.201000137.

34. P. Saravanapavan and L. L. Hench, "Mesoporous calcium silicate glasses. I. Synthesis," J. Non. Cryst. Solids, vol. 318, no. 1-2, pp. 1-13, Apr. 2003, doi: 10.1016/S0022-3093(02)01864-1.

35. A. S. A. Raboh, M. S. El-khooly, and M. Y. Hassaan, "Bioactivity and Drug Release Study of Dexamethasone Loaded Bioglass/Chitosan Composites for Biomedical Applications," $J$. Inorg. Organomet. Polym. Mater., vol. 1, p. 3, Feb. 2021, doi: 10.1007/s10904-021-01936-z.

36. H. Oudadesse, X.-V. Bui, Y. Le Gal, A. Mostafa, and G. Cathelineau, "Chitosan Effects on Bioactive Glass for Application as Biocopmosite Biomaterial," Int. J. Biol. Biomed. Eng., vol. 5, no. 2, p. 558, 2011

37. M. Nitsae, A. Madjid, L. Hakim, and A. Sabarudin, "Preparation of chitosan beads using tripolyphosphate and ethylene glycol diglycidyl ether as crosslinker for $\mathrm{Cr}(\mathrm{VI})$ adsorption," Chem. Chem. Technol., vol. 10, no. 1, pp. 105-114, 2016, doi: 10.23939/chcht10.01.105.

38. M. A. Moharram, K. M. T. Ereiba, W. El Hotaby, and A. M. Bakr, "Synthesis and characterization of graphene oxide/crosslinked chitosan nanaocomposite for lead removal form aqueous solution,” Res. J. Pharm. Biol. Chem. Sci., vol. 6, no. 4, pp. 1473-1489, 2015. 


\section{"دراسة النثاط الحيوي لهجين من الزجاج الحيوي والكيتوزان والمطعم بكبريتات

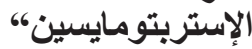 \\ عبدالرحمن عبدالرحمن الاسنوي ، أحمد صابر عبدربه ، أحمد بكر ، خيري محمد تهامي عريبة

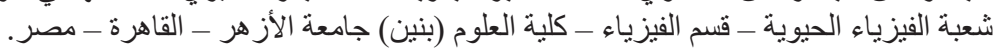

فى هذه الدر اسة تم تحضير نظام توصيل دو ائي جديد فى صورة (Scaffold) ينكون من (الزجاج الحيوي

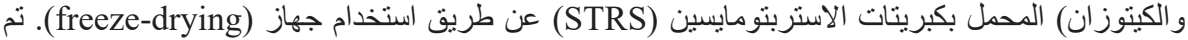

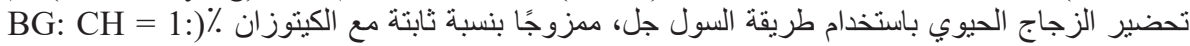

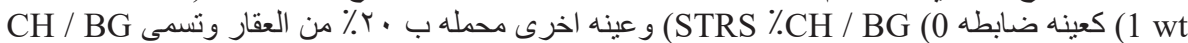

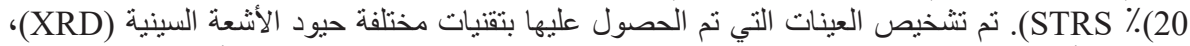

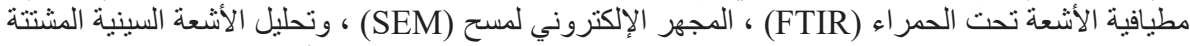

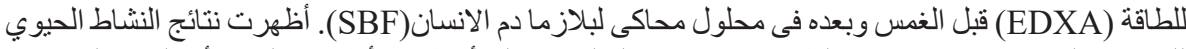

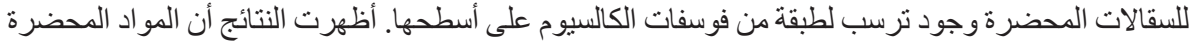
(STRS \%.CH / BG (20

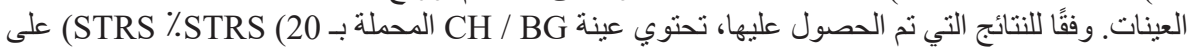

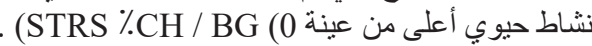

